decades since Halsted until it was more or less forced on surgeons (and others) who treated the necessity of radical operation as an article of faith. Finally, Professor Dudley's statement: "It was deemed necessary to use a randomised trial" for streptomycin in tuberculosis is not quite what he terms "a good historical example." If he is referring to the early British trial of streptomycin for meningeal tuberculosis, it is widely understood that that trial was forced on the investigators by a shortage of streptomycin.

With these important exceptions Professor Dudley's paper remains a powerful thinkpiece which is, in spirit, an important contribution to any debate about appropriate clinical trials.

David H SPODICK

University of Massachusetts

Medical School,

St Vincent

Worcester,

Spodick DH. Randomized controlled clinical trials the behavioral case. $\mathcal{F} A M A \quad 1982 ; 247: 2258-60$

Spodick DH. The randomized controlled clinica trial: Scientific and ethical bases. $A m \mathcal{F} \mathrm{Med}$ $1982 ; 73: 420-5$

Sacks H, Chalmers TC, Smith H Jr. Randomized versus historical controls for clinical trials. $A m \mathcal{F} M e d$ $1982 ; 72: 233-40$.

Am $\mathcal{F}$ Ophthalmol 1975;79:753-8.
.

Haemophilus influenzae type $b$ resistant to ampicillin and chloramphenicol

SIR,-We report a further case of infection with a strain of Haemophilus influenzae type b resistant to both ampicillin and chloramphenicol, similar to that reported by Dr Ronan J P Garvey and Dr G Peter McMullin (22 October, p 1183).

A 9 month old girl was diagnosed in February 1982 as having tonsillitis. One month before otitis media had been treated with amoxycillin for 10 days. Nasopharyngeal swabs were taken and cultures on blood and chocolate agar yielded Haemophilus influenzae type $\mathrm{b}$, resistant to ampicillin and chloramphenicol. The patient recovered after treatment with erythromycin for 10 days. Nasopharyngeal swabs were taken from household contacts (mother and father); a strain of $H$ influenzae type b resistant to ampicillin and chloramphenicol was isolated from the mother and a non-typable strain sensitive to both antibiotics was isolated from the father.

The isolates were identified as $H$ influenzae by standard techniques and were typed with specific antisera (Wellcome Foundation Ltd) by slide agglutination. $\beta$ Lactamase activity was shown by the chromogenic cephalosporin assay and by the method of McGhie et al. ${ }^{1}$ The minimal inhibitory concentration of chloramphenicol was $16 \mu \mathrm{g} / \mathrm{ml}$ and that of ampicillin $8 \mu \mathrm{g} / \mathrm{ml}$, using the agar dilution method.

Transfer studies were carried out by membrane filter method. ${ }^{2}$ The recipient was an Escherichia coli $\mathrm{K} 12$ chromosomal resistant to nalidixic acid. No transconjugants were identified on the selective medium with $32 \mu \mathrm{g} / \mathrm{ml}$ ampicillin plus $50 \mu \mathrm{g} / \mathrm{ml}$ nalidixic acid nor with $32 \mu \mathrm{g} / \mathrm{ml}$ chloramphenicol plus $50 \mu \mathrm{g} / \mathrm{ml}$ nalidixic acid.

Plasmid DNA extraction was performed as described by Meyers et al. ${ }^{3}$ The electrophoresis was carried out in a $0.7 \%$ vertical agarose gel. A strain $E$ coli v517 was used as internal molecular weight standard. No plasmid bands were seen but only the chromosomal location.

Surveillance of antibiotic resistance in $H$ influenzae has been under way in the Lisbon area since 1978 . The incidence of resistance to ampicillin in 150 strains examined in 1982 was $4.3 \%$. Though strains resistant to ampicillin and chloramphenicol have previously been reported in Bangkok ${ }^{4}$ and in Britain, ${ }^{5}$ to our knowledge this was the first time that such a strain was isolated in Portugal.

We are grateful to Dr H Martins for permission to report details of this case.

\section{A CATRY} M V VAz Pato

Laboratório de Bacteriologica,

Instituto Nacional de Saúde,

1699-Lisboa Codex,

' McGhie D, Clarke P, Johnson T, Hutchinson JG. Detection of beta lactamase activity of Haemophilus influenzae. F Clin Pathol 1977;30:585.

, Thornsberry C. Transfer of beta lactanorrhoea by conjugation Antimicrob Agents Chemother 1977;6:1004-6.

Meyers JA, Sanchez D, Elwell L, Falkow S. Simple agarose gel electrophoretic method for the identification and characterisation of plasmid deoxyribonucleic acid. $\mathcal{F}$ Bacteriol 1976;127:1529-37.

- Simasathien S, Duangmani C, Echeverria P. Haemophilus influenzae type $B$ resistant to ampicillin and chloramphenicol in an

MacMahon P, Sills J, Hall E, Fitzgerald T. Haemophilus influenza type b resistant to both chloram phenicol and ampicillin in Britain. Br Med $\mathcal{J} 1982$ 284:1229.

\section{Mean platelet volume in myocardial infarction}

SIR,-Dr H A Cameron and others (13 August, p 449) and Dr J F Martin and others (13 August, p 456) reported an increased mean platelet volume in patients with myocardial infarction compared with controls without cardiac disease. Mean platelet volume has been shown to be inversely and non-linearly related to platelet count, both in normal controls and in a hospital population. ${ }^{12}$ In the study by $\mathrm{Dr}$ Cameron and others platelet counts are not mentioned, but Dr Martin and others found significantly lower platelet counts in the patients suffering myocardial infarction than in their controls. From this a higher mean platelet volume in the patients with infarction could be expected. Whether an increased mean platelet volume predisposes for myocardial infarction cannot be concluded from these findings.

The results of Dr Cameron and others and Dr Martin and others led us to study mean platelet volume prospectively in all patients admitted to our coronary care unit during a four week period. The total number of patients admitted was 72,12 of whom had myocardial infarction. Twenty two patients had angina pectoris; infarction was excluded enzymatically. The other 38 patients represent a heterogeneous group, including 19 patients with congestive heart failure or dysrhythmias, or both, and 19 patients without cardiac disease. Mean platelet volume and platelet number were measured from one to six hours after collection, using a Coulter counter model $S$ plus 2 , in whole blood anticoagulated with edetic acid obtained from all patients shortly after admission. The results are shown in nomogram for the relation between the mean platelet volume and platelet count, derived from 949 hospital patients with normal values for white cell count, lymphocyte percentage, haemoglobin, and red cell indices. Mean platelet volume and platelet count in the patients who had suffered infarction (mean $6.5 \mathrm{fl}$ (SE 0.6 ) and $243 \times 10^{9} / 1$ (SE 28)) were no different from the values found in the patients with angina pectoris (mean $6.5 \mathrm{fl}$ (SE 0.3) and $238 \times 10^{\circ} / 1$ (SE 15)) or in the patients without acute cardiac ischaemia (mean $7.0 \mathrm{fl}$ (SE 0.2) and $240 \times 10^{\circ} / 1($ SE 17))

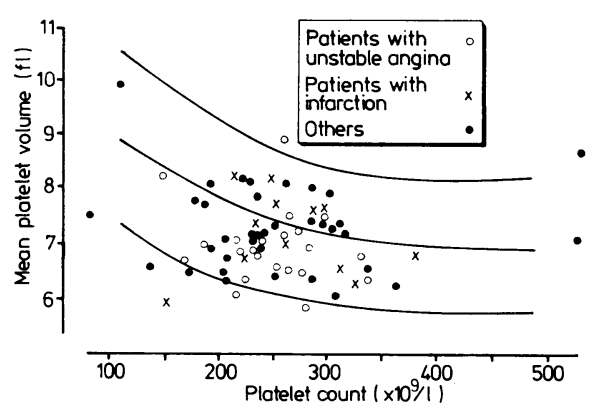

Nomogram for relation between platelet volume and platelet count in 72 patients admitted to coronary care unit.

We conclude that measurement of the mean platelet volume in the coronary care unit has no clinical relevance.

J VAN DER LELIE J A C BRAKENHOFF

Department of Internal

Medicine and Cardiology,

Academic Medical Cen

1105 AZ Amsterdan

Giles C. The platelet count and mean platelet volume.

Giles C. The platelet count and mean platelet volume.
Br f Haematol 1981;48:31-7. pin J, Bessman JD: The inverse relation between platelet volume and pl
Med 1983;101:295-307.

Rupture or leakage of atheromatous arteries or aneurysms and salmonella infection

SIR,-The recent report of two cases of septic arteritis from salmonellosis by $\operatorname{Dr} P$ H Winocour and others (1 October, p 972) prompted me to make some comments on another aspect of salmonellosis after briefly reporting our experience with another case.

A 76 year old diabetic woman started complaining of pain on the right side of her abdomen, right thigh, and on her back after about 10 days of hospital admission. She had had bouts of diarrhoea and a rise in temperature one week before admission. Investigations including stool culture and microscopy did not show any important findings other than urinary infection with Escherichia coli. This was treated initially with co-trimoxazole then with cephalexin. She developed diarrhoea one week later. Stool culture again did not show any pathogen and her diarrhoea was thought to be due to antibiotics, which were than stopped. The patient's general condition started deteriorating. Blood cultures taken at this stage grew a salmonella, but the patient died before result of culture was known. Important findings at necropsy were a leaking atheromatous aneurysm on the abdominal aorta and thrombosis of the inferior vena cava at about the centre of the aneurysm. Culture of swabs from the area of leakage over the aneurysm grew the same salmonella, which was later identified as $S$ dublin by the reference laboratory in London.

This case differed from those of $\mathrm{Dr}$ Winocour and his colleagues in that the salmonella was never cultured from faeces. Failure to grow the salmonella from faeces might have been due to the use of antibiotics for treating her urinary infection. While agreeing with the comments of $\mathrm{Dr}$ Winocour and his colleagues, I wish to make a further observation. Metastatic infection from salmonella is well known. But it may not be so well known that salmonella had been associated with 